\title{
Georg Simmel y la sociología económica: el mercado, las formas sociales y el análisis estratégico*
}

\section{Roberto Herranz González}

Universidad de Santiago de Compostela. Departamento de Sociología Avda. do Burgo, s/n. 15704 Santiago de Compostela cpherran@usc.es

\section{Resumen}

En diversos fragmentos de la obra de Simmel se esconden los fundamentos de una sociología del mercado que considera los procesos de racionalización de la estructura social y los espacios de interacción. Para demostrarlo, comenzamos relacionando la división del trabajo con las redes sociales y los procesos de innovación; a continuación, abordamos los procesos de racionalización que influyen en la naturaleza de los mercados; finalmente, a partir de sus ensayos y articulando diversas formas sociales, podemos contemplar el mercado como un espacio de relaciones sociales. Estas formas son: el intercambio, la competencia, la confianza y la negociación.

Palabras clave: división del trabajo, innovación, redes, Simmel, sociología económica, sociología del mercado, formas sociales.

\section{Abstract. George Simmel and the Economic Sociology: Market, Social Forms and Strategic Analysis}

In a few fragments of the Simmel's work we can discover a sociology of the market which contemplate the rationalisation of social structure and the space of social interaction. With this aim, we begin our article relating the division of labour with the social networks and the innovation; in the next step we focuses our interest in the process of rationalisation, indicating its influence in the nature of market; finally, from Simmel's essays and articulating divers social forms, we can contemplate the market as a space of social relations. These social forms are: interchange, competence, trust and bargaining.

Key words: division of labour, economic sociology, innovation, social forms, social networks, sociology of markets.

\section{Sumario}

1. Introducción 4. A modo de conclusión

2. La innovación, el medio urbano Referencias bibliográficas y la racionalización de los mercados

3. El mercado como un espacio de interacción social

* Este trabajo se ha realizado dentro de las actividades del grupo de investigación del proyecto SEJ 2004-00447 del MEC. Deseo agradecer al profesor Dr. Félix Requena Santos los comentarios que me ha hecho para la preparación del texto. 


\section{Introducción}

En este artículo se rescatan algunas de las aportaciones de Simmel al estudio sociológico del mercado. En la obra de Simmel, como en la de Weber o en la de Durkheim, es posible descubrir algunos de los fundamentos de la nueva sociología económica, en la que el mercado ocupa un lugar privilegiado en la agenda de investigación ${ }^{1}$.

Su trabajo mantiene una estrecha relación con algunas de las orientaciones de la nueva sociología económica, al interesarse por los procesos económicos en términos de interacciones sociales, sin olvidar el papel de las estructuras sociales e institucionales más cristalizadas ${ }^{2}$.

Sin embargo, las referencias directas a Simmel son muy limitadas, están casi ausentes en los textos ${ }^{3} \mathrm{y}$ en los trabajos de reconstrucción histórica de esta disciplina ${ }^{4}$. Esta ausencia tal vez podría explicarse, porque, a diferencia de Durkheim o Weber, nuestro autor no se propuso definir la sociología económica como un campo de estudio. Su interés se decantó por una sociología de las formas sociales 5 , perspectiva que fue cuestionada por Weber, por Durkheim y más tarde por Parsons ${ }^{6}$.

Aunque en sus trabajos no aborda el estudio del mercado de un modo unitario, en sus "formas sociales» encontramos un conjunto de reflexiones que, debidamente articuladas, permiten representarlo en términos de interacciones sociales.

Los argumentos de este artículo se han extraído en parte de su Filosofía del dinero $^{7}$, pero sobre todo de sus ensayos sobre las formas sociales, donde se encuentran buenos ejemplos relativos al mercado.

1. Steiner, Ph. (2002). La sociologie économique. París: La Découverte; Fligstein, N., "Agreements, Disagreements and Opportunities in the "New Sociology of Markets"». En: Mauro F. Guillen, Randall Collins, Paula England, Marshall Meyer. The New Economic Sociology. Developments in a Emerging Field. Russell Sage Foundation, p. 61 y s.

2. Éste es el caso del trabajo de Marc Granovetter, que ha adquirido el estatus de texto fundacional (GranovetTer, M. «Economic Action and Social Structure: The Problem of Embeddedness». American Journal of Sociology, vol. 91, 1985, p. 481-510, traducción española en REQUENA SANTOS, F. (2003). Análisis de redes sociales: Orígenes, teorías y aplicaciones. Madrid: Centro de Investigaciones Sociológicas).

3. Smelser, N. J., Swedberg, R. (1994). Handbook of Economic Sociology. Nueva Jersey: Princeton University; INGHAM, G. (1996). «Some Recent Changes in the Relationship between Economics and Sociology». Cambridge Journal of Economics, vol. 20, no 2, marzo, p. 243-275.

4. Swedberg, R. (1987). «Economic Sociology: Past and Present». Current Sociology, vol. 1.

5. Simmel, G. (1986). El individuo y la libertad. Ensayos de critica de la cultura. Barcelona: Península, p. 244.

6. García Blanco, J. M. (2000). "Sociología y sociedad en Simmel». Revista Española de Investigaciones Sociológicas, 89, enero-marzo, p. 109-113.

7. Simmel, G. (1977). Filosofía del dinero. Madrid: Instituto de Estudios Políticos. 


\section{La innovación, el medio urbano y la racionalización de los mercados}

En lo que sigue, comenzaremos dando cuenta del papel de las redes sociales en los procesos de innovación, para abordar, a continuación, el espacio urbano como un lugar que ha sido testigo privilegiado de intensos procesos de innovación y de racionalización. Estos procesos afectaron a la naturaleza de los mercados, a la relación entre los actores, a la variedad de productos y a las formas mediante las cuales se establecen los intercambios.

\section{Las redes sociales y la innovación}

A lo largo de su obra Simmel reflexiona sobre los procesos de cambio en la estructura social. En ella estudia la naturaleza de las redes sociales, los grupos y círculos que se solapan y el papel que estos vínculos desempeñan en los procesos de cambio y de innovación.

Con la división del trabajo aparecen nuevos grupos, éstos aumentan de tamaño y, a su vez, se desarrollan nuevas formas de integración y de comunicación. Gracias a la división del trabajo, es posible una nueva forma de unidad derivada de las múltiples relaciones de dependencia y, de este modo, se impide la desintegración de la sociedad ${ }^{8}$. En este escenario, el individuo es, al mismo tiempo, más dependiente y más libre, pues, por un lado, depende de muchos proveedores y, por otro, tiene más grados de libertad para elegir entre ellos?.

Debido al proceso de modernización, los grupos aislados, cerrados sobre sí mismos, se ven obligados a comunicarse a través de las interdependencias que se crean, apareciendo un tejido de círculos de afiliación que se cruzan y que facilita el comportamiento innovador. La pertenencia del individuo a múltiples círculos permite una gran cantidad de "oportunidades individualizadoras ${ }^{10}$, de modo que cada punto del tejido social queda expuesto a nuevas ideas gracias a las cuales se desarrolla "la innovación».

En su ensayo Digresión sobre el extranjero, cuando relaciona la figura del comerciante con la del extranjero, podemos leer: «Sólo el comercio crea infinitas combinaciones; merced a él, la inteligencia halla constantemente ampliaciones y nuevas fuentes, lo que difícilmente se les ocurriría a los productores con escasa movilidad y habituados como se hallan a un círculo de clientes que muy lentamente varía» ${ }^{11}$. Además el extranjero, al no pertenecer al grupo desde su inicio, está menos expuesto a sus hábitos y formas de pensamiento.

En este sentido, Coser, inspirándose en Simmel, comenta cómo aquéllos que ocupan posiciones marginales «[...] están motivados para entregarse a una conducta innovadora a causa de que están inducidos estructuralmente a apar-

8. Simmel, G. (1986), Sociología. Estudios sobre la socialización, Madrid, Alianza Editorial, p. 58.

9. Ibídem, p. 195.

10. Ibídem, p. 448.

11. Ibídem, p. 717. 
tarse de las normas sociales prevalentes» ${ }^{12}$. Por el contrario, unas relaciones sociales muy estrechas y aisladas suponen un obstáculo para la innovación y el cambio ${ }^{13}$. Sobre la naturaleza local y cosmopolita de los círculos sociales y su relación con la innovación, se ha desarrollado una extensa literatura sociológica inspirada en el análisis de las redes ${ }^{14}$.

La gran metrópoli de finales del siglo XIX es un lugar privilegiado como incubadora de los procesos de innovación. Ella es testigo de procesos de racionalización que se estaban produciendo en las sociedades europeas a finales del siglo XIX. En relación con este extremo, los argumentos de Simmel son próximos a los de muchos otros clásicos. Como señala Carlota Solé, es «en las ciudades donde aparecen fenómenos nuevos y únicos, como son la racionalización, la burocratización o la urbanización. El desarrollo de las ciudades en Occidente es la premisa de que parte Weber (también lo presuponen Tönnies y Simmel) para explicar el desarrollo del capitalismo» ${ }^{15}$.

Para Simmel, Berlín será el escenario privilegiado para dar cuenta de los procesos de innovación y de racionalización. «Berlín — nos dice M. Castells ${ }^{16}$ entre 1880 y 1914, fue un ejemplo clásico y en realidad no fue sino el Silicon Valley de su época». En las grandes urbes, se conjugan algunas de las condiciones que fomentan el proceso de innovación. La mayor libertad de las relaciones internas y externas es una fuente de nuevas ideas, el volumen de población facilita la absorción de una oferta de productos más diversificada y la competencia estimula la especialización. De un modo paralelo a la creciente división del trabajo, se asiste a una diferenciación de los mercados.

En comparación con las sociedades anteriores, nos dice el sociólogo alemán, se "ha transformado la lucha con la naturaleza para la adquisición de alimentos en una lucha por los hombres». Y, en este sentido, propone una de las ideas vertebrales de su concepción de los mercados: «[...] aquí no sólo fluye la fuente precisamente aludida de la especialización, sino la más profunda: el que ofrece debe buscar provocar en el cortejado necesidades siempre nuevas y específicas. La necesidad de especializar la prestación para encontrar una fuente de ganancia no agotada, una función no fácilmente sustituible, exige la diferenciación, refinamiento y enriquecimiento de las necesidades del público» ${ }^{17}$.

12. Coser, L. (1970). Nuevos apuntes a la teoría del conflicto social. Buenos Aires: Amorrortu, p. 122.

13. Un coste que implica la sociabilidad, apunta Alejandro Portes, «son las limitaciones que las normas de la comunidad imponen sobre la conducta de los individuos y su capacidad de innovación» (PORTES, A. «Economic Sociology and the Sociology of Inmigration: a Conceptual Overview». En: PORTES, A. (ed.) (1995). The Economic Sociology of Inmigration. Nueva York: Russel Sage Foundation, p. 15-16).

14. Degenne, A.; Forsé, M. (2004). Lés réseaux sociaux. París: Armand Colin, p. 189-191.

15. SOlÉ, C. (1998). Modernidad y modernización. Barcelona: Anthropos, p. 64.

16. Castells, M.; Hall, P. (1994). Las tecnópolis del mundo. Madrid: Alianza Editorial, p. 210.

17. Simmel, G. «Las grandes urbes y la vida del espíritu». En: Simmel, G. El individuo y la libertad, o. c., p. 258. 
Estas nuevas necesidades de diferenciación y de refinamiento estarían asociadas al estilo de vida urbano y serían fruto de las nuevas condiciones de existencia. La frecuencia de encuentros sociales muy breves con individuos diferentes explicaría la necesidad de sobresalir y de impresionar de una sociedad sometida a un ritmo acelerado y a una estricta organización del tiempo.

\section{La racionalización de la vida urbana y los mercados}

La ciudad es también el espacio de la racionalización por excelencia que favorece la determinación y la fluidez de la vida mercantil. La puntualidad, la calculabilidad, la precisión, el carácter inequívoco de los acuerdos, la justicia formal son rasgos de una nueva cultura que se expresa en las grandes ciudades. Esta cultura que acompaña al crecimiento de la economía monetaria, crea unas nuevas condiciones que facilitan la cooperación compleja, el crecimiento de la circulación mercantil y el desarrollo de los mercados.

En efecto, la racionalización invade todos los ámbitos del circuito socioeconómico, es decir, desde la producción del conocimiento, la fabricación y los sistemas de transporte a los espacios de consumo que se desarrollan en torno a los grandes almacenes a finales del siglo XIX. En este escenario, aparecen nuevos productos creados por la ciencia, nuevos modos de organización, nuevos conocimientos que se da por sentados y que, en buena medida, somos incapaces de comprender ${ }^{18}$. Por este motivo, se hace más evidente una fractura entre la cultura objetiva y la subjetiva, que se revela en la especialización de los productores, en su separación respecto al producto ${ }^{19}$ y, finalmente, en la separación entre el productor y el consumidor. De este modo, se transforma la naturaleza de la producción y la naturaleza de los mercados.

Los mercados pasan de ser dominantemente asociativos a ser dominantemente disociativos, pues ya no es necesario que el comprador y el vendedor participen conjuntamente en el diseño ${ }^{20}$. Mientras en los sistemas menos diferenciados el cliente podía participar conjuntamente con el fabricante en el diseño del producto, en los sistemas modernos el productor se orienta con más frecuencia hacia un consumidor anónimo ${ }^{21}$. El consumo adquiere un carácter impersonal que contribuye a homogeneizar los deseos y permite el abara-

18. Simmel, G. Filosofía del dinero, o. c., p. 564.

19. Ibídem, 574-575. En ésta y otras reflexiones presentes en su Filosofía del dinero se reconoce la influencia de Marx. Tampoco habría que olvidar los comentarios críticos que hace de la teoría del valor trabajo (ibídem, p. 510-534).

20. Cfr. Aspers, P. (2006). «Markets Structures». En: BeCKERT, J., ZAFIROVsKI, M., International Enciclopedy of Economic Sociology. Londres: Routledge, p. 431.

21. Nótese aquí la presencia de dos tipos de mercado caracterizados por formas de acción y relación social diferentes (Cfr. ORTEGA Y GASSET, José (1986). «Los escaparates mandan». El Sol, 15 de mayo de 1927. En: ORTEGA y GASSET, José. La rebelión de las masas. Madrid: Espasa Calpe). El tipo de relación entre el productor y el cliente sigue siendo de enorme interés para caracterizar a los mercados y observar las formas de cooperación y de aprendizaje que pueden presentarse. 
tamiento de los bienes ${ }^{22}$, de modo que, con su racionalización, el hombre se rodea de una multitud de productos menos duraderos y menos adheridos a su personalidad $^{23}$.

Aparte de subrayar el crecimiento de la producción en masa, Simmel revela, como no se había hecho hasta el momento ${ }^{24}$, la fuerza de las orientaciones hacia el consumo en la definición de la identidad de los individuos. Precisamente cuando la sociedad de consumo de masas comienza a germinar, adquiere pleno sentido el ensayo sobre la moda.

La moda se enfrenta a la homogeneización del consumo que pone en peligro la señalización de las diferencias sociales. La moda, al ir a contracorriente de la estandarización, limita los progresos de una organización de la producción basada en la normalización y la previsión. En sus palabras: «El tempo de su evolución es de tal relevancia en los auténticos artículos de moda que llega incluso a sustraer a éstos de ciertos progresos de la economía gradualmente alcanzados en otros ámbitos» ${ }^{25}$. Se diría que, frente a los modelos de naturaleza burocrática, de cuya rigidez daba cuenta Simmel ${ }^{26}$, comienzan a desarrollarse espacios de producción más flexibles y orgánicos que, con el tiempo, caracterizarán a un nuevo paradigma productivo.

El valor de la moda, al estar asociado a la búsqueda de la distinción, descansa en su transitoriedad, pues un artículo de moda pierde su valor en la medida en que da muestra de su éxito a través de la imitación. La moda expresa una forma de segmentación en el mercado de consumo y es un bien posicional por excelencia que constituye un fenómeno a la vez cultural, económico y social. La moda es fruto de las necesidades de integración y de distinción de los grupos privilegiados, se inserta en una organización precisa de la economía y, finalmente, constituye un producto de la división de la sociedad en clases $^{27}$.

El estudio de la moda, que interesó a autores como Cooley, Veblen y Blumer, nos sitúa en los fundamentos de una economía de la producción simbólica de las mercancías. El nuevo producto del que se reviste la mercancía y que contribuye a crearla es la imagen. A través de ella, se busca incrementar la renovación de los productos mediante la aceleración planificada de la obsolescencia social.

\section{El mercado como un espacio de interacción social}

Tras abordar brevemente el papel de las innovaciones y de la racionalización del espacio urbano en la configuración y en la diferenciación de los mercados,

22. Simmel, G. Filosofía del dinero, o. c., p. 572-573.

23. Ibídem, p. 579.

24. Castillo Castillo, J. (1996). "Trabajo y consumo». En: OrTega, F. y otros. Fundamentos de Sociología. Madrid: Síntesis; LAMO DE EsPINOSA, E. y otros (1994). La sociología del conocimiento y de la ciencia. Madrid: Alianza Universidad.

25. Simmel, G. (1988). Sobre la aventura. Ensayos filosóficos. Barcelona: Península, p. 52.

26. SimMEL, G. Sociología, o. c., p. 595.

27. Simmel, G. Sobre la aventura. Ensayos filosóficos, o. c., p. 26 y s.; SimMEL, G. Filosofia del dinero, o. c., p. 580-582. 
veremos de qué modo Simmel contempla las relaciones sociales del mercado. Lo haremos a través de formas sociales como el intercambio, el dinero, la competencia, la confianza y la negociación. De un modo próximo a Weber, podríamos definir el mercado como un espacio de interacción social con motivo del intercambio y bajo condiciones de competencia y de regateo ${ }^{28}$.

\section{El dinero, el intercambio y la competencia}

Simmel considera que el intercambio económico no es más que un caso particular de intercambio social, que también está fundado sobre relaciones recíprocas. $\mathrm{Al}$ interesarse por el intercambio, Simmel va más allá del intercambio formalizado, e insiste en cómo, a través de estos procesos de interacción, se generan prestaciones y contraprestaciones que no tienen un carácter formal y que contribuyen a la mutua trabazón social.

En la Filosofía del dinero, Simmel analiza el intercambio económico en su forma más pura como un proceso de creación de valor que se expresa en dinero, mediante un sistema de equivalencia que objetiva las relaciones. El dinero, que mide la distancia que nos separa de los objetos, se presenta como un medio para adquirir el bien deseado y expresa el valor de las cosas en su calidad de intercambiables ${ }^{29}$. En realidad, es el medio generalizado de intercambio $^{30}$.

En relación con las múltiples apreciaciones que ha hecho Simmel sobre el significado del dinero en la sociedad moderna, a nosotros nos interesa destacar que el dinero es una institución social. El dinero es una «institución social» que «supone una organización social y unas normas suprasubjetivas». La define como: «[...] nuestra creación en el mundo exterior por cuanto, por un lado, está completamente configurada por nuestras fuerzas y, por otro, se integra perfectamente en nuestros órdenes intencionales» ${ }^{31}$. Se reconoce aquí el proceso de institucionalización del que nos da cuenta la obra de Peter L. Berger y Thomas Luckmann ${ }^{32}$.

Esta institución social agiliza las transacciones y, a diferencia del pago en especie, permite decidir con libertad en qué gastarlo, cuándo y dónde ${ }^{33}$, razón por la cual la posibilidad de la elección es una ventaja que ha de añadirse al

28. Max Weber, en el capítulo VI —y en el capítulo II - de Economía y sociedad entiende el mercado en términos de un espacio de interacción social con motivo del «intercambio» y que tiene lugar bajo condiciones de "competencia» y de «regateo» (WEBER, Max. Economía y sociedad, o. c.).

29. Simmel, G. Filosofía del dinero, o. c., p. 113.

30. Cfr. Deutschmann, Cr. "Capitalism as a Religion? An Unortodox Analysis of Entrepreneurship, The Return of Economic Sociology in Europe». European Journal of Social Theory, 4 (4): 387-403, p. 392.

31. Ibídem, p. 234-236.

32. Berger, P., Luckman, T. (1972). La construcción social de la realidad. Buenos Aires: Amorrortu.

33. Simmel, G. Filosofía del dinero, o. c., p. 241. 
valor del dinero ${ }^{34}$. Pero tan sólo los que disponen de mucho dinero pueden liberarse de las necesidades más apremiantes que comprometen de antemano buena parte de los ingresos ${ }^{35}$. Por este motivo, el rico tiene poder no sólo por lo que hace, sino también por lo que podría hacer. El grado de incertidumbre que puede crear es tanto mayor "cuanto mayor movilidad tiene la fortuna" ${ }^{36}$. La economía financiera se enfrenta aquí a la socioeconomía, comparativamente más inelástica, menos móvil, menos divisible, más vinculada a la vida. Es precisamente la capacidad para desubicarse y para deslocalizarse lo que concede a esas grandes fortunas una gran capacidad para manejar la incertidumbre $y$, en consecuencia, para incrementar su poder.

A pesar de todo, es decir, del poder que permite el dinero, su uso está condicionado por las formas legítimas de circulación monetaria ${ }^{37}$ que varían históricamente. En la Filosofía del dinero se da cuenta del progreso histórico de la idea de la vida humana como un valor absoluto, del significado de la prostitución, del soborno y de la corrupción. En esta línea, Viviana Zelizer se ha preocupado por estudiar las condiciones sociales que han obstaculizado o impedido el desarrollo de mercados, como el de los seguros de vida o el mercado de bebés ${ }^{38}$.

Tanto la construcción social de la mercabilidad como los debates y los conflictos sociales que se producen en torno a ella son temas primordiales para la sociología económica ${ }^{39}$.

Una segunda forma social que nos interesa en la reconstrucción de la idea de mercado es la competencia. Simmel aborda el estudio de la competencia en el contexto de sus reflexiones sobre el conflicto y la lucha.

La competencia bajo su forma más ideal y estilizada es un tipo de lucha que Simmel define como indirecta ${ }^{40}$. Es indirecta, pues, a pesar de que quienes participan en ella buscan ganar o sobrepasar a sus rivales, su destrucción no es el objetivo prioritario. El daño o el castigo que puede sufrir el perdedor es un efecto derivado de ella. Y algo más adelante sostiene que el tipo de competencia que más se aleja de otras luchas es aquélla en la que «cada uno de los que en ella participa va hacia el objetivo sin emplear su fuerza contra el adversario» ${ }^{41}$.

Lo importante de la competencia es que la lucha entre los concurrentes se orienta hacia un tercero, al que se trata de conquistar mediante diversos recla-

34. Ibídem, p. 239.

35. Ibídem, p. 248.

36. Ibídem, p. 247-248.

37. Ibídem, p. 484.

38. ZELIZER, V. (1978). «Human Values and the Market: the Case of Life Insurance and Death in $19^{\text {th }}$ Century America». American Journal of Sociology, 84, p. 591-610; ZELIZER, V. (1992). "Repenser le marché, la construction sociale du "marché aux bebés” aux États-Unis, 18701930». Actes de la recherche en sciences sociales, 94, septiembre.

39. Block, F. (1990). Posindustrial Possibilities. A Critique of Economics Discourse. Berkeley: University California Press, p. 56 y s.

40. Simmel, G. Sociología. Estudios sobre la socialización o. c., p. 300.

41. Ibídem, p. 301. 
mos. «El ejemplo más amplio de tertius gaudens es el público comprador en una economía de competencia libre» ${ }^{42}$.

En este juego, el comprador tiene la última palabra para elegir entre las diversas ofertas. En condiciones de competencia entre proveedores, los consumidores buscarían ajustar su compra según sus exigencias de calidad y de precio en las mercancías. Por su parte, los proveedores intentarían descubrir «los deseos inexpresados o inconscientes del consumidor, sugiriéndole otros que no tiene o habituándole a ellos» ${ }^{43}$. En consecuencia, bajo la presión de la competencia, los proveedores pueden influir en los deseos, en las necesidades y en las preferencias de los consumidores; sus demandas pueden transformarse endógenamente en el contexto de la interacción social que se produce en el mercado.

A diferencia del conflicto, el resultado de la competencia no se limita a la victoria o a la derrota de los que participan en ella. La competencia también trae consigo efectos positivos o virtuosos para el conjunto de la sociedad. En realidad, son efectos latentes que no son ni pretendidos ni esperados por los que participan directamente en ella y que permiten satisfacer mejor las necesidades de los consumidores.

Simmel es consciente de los efectos destructivos de la competencia, hasta el punto de que, bajo determinadas condiciones, los adversarios pueden quedar excluidos del mercado, y sus productos, eliminados, por lo que resultan vanos todos los esfuerzos realizados para producirlos.

A pesar de este derroche, el respaldo social a la competencia se explicaría por los efectos beneficiosos que tendría para la sociedad, de modo que, haciendo un balance, las ventajas que trae consigo serían superiores a las pérdidas ${ }^{44}$. Por ello, el puro interés de la sociedad puede no sólo permitir, sino también provocar expresamente la competencia ${ }^{45}$.

Además, la competencia en el mercado no sólo separa, sino que también contribuye a la integración social, lo cual genera múltiples efectos socializadores y estimula el aprendizaje. La competencia genera una estructura social de incentivos que contribuye a la transformación de los lazos sociales y de sus contenidos.

En efecto, el enorme poder socializador de la competencia «obliga al competidor a salir al encuentro del tercero, a satisfacer sus gustos, a ligarse a él, a estudiar sus puntos fuertes y débiles para adaptarse a ellos» ${ }^{46}$. La tensión de la competencia estimula el aprendizaje, dado que "afina en el comerciante la sensibilidad para percibir la inclinación del público y llega a dotarle de una especie de instinto adivinatorio para las mutaciones inminentes de sus gustos, de sus modas [y] de sus intereses» ${ }^{47}$. 
El mercado se expresa aquí en términos dinámicos y no estáticos, $\mathrm{y}$, a través del él, se alteran no sólo los actores y su lugar en la competencia, sino que también se define y se redefine la naturaleza de lo que se intercambia ${ }^{48}$. Estas transformaciones de tipo endógeno al mercado nos dan cuenta de los procesos evolutivos que tienen lugar como consecuencia de la interdependencia entre la oferta y la demanda.

Para Simmel, este esfuerzo por ser reconocido y aceptado en el mercado adquiere una intensidad que no hubiese sido posible sin la comparación constante impuesta por la competencia ${ }^{49}$. La competencia constituye un sistema de control impersonal.

Precisamente por estos motivos, la sociedad puede defender la utilidad social de la competencia, razón por la cual establece unas reglas de juego que eviten la deslealtad y sanciona determinados actos que también se castigan en las relaciones humanas como la violencia, la falsedad o la mentira ${ }^{50}$. Pero, aparte de estas restricciones, la competencia en el mercado puede verse afectada, $y$ en el límite, eliminada, por factores culturales. En relación con este tema, apunta que «la moral típica europea muestra más tolerancia frente a la competencia que frente a otros tipos de antagonismos» ${ }^{51}$.

Del mismo modo que la sociedad puede apreciar la competencia de formas diversas, sus resultados pueden adquirir diversos significados para los actores implicados en ella. Por ejemplo, cuando no están vinculados al esfuerzo, los participantes estarán dominados por la «indiferencia», la irritación o la envidia, lo que nos conduciría a considerar el problema de la equidad y de la privación relativa en el contexto del mercado ${ }^{52}$.

Finalmente, Simmel no se olvida de que aquéllos que compiten entre sí pueden, al mismo tiempo, mantener una relación de cooperación. En efecto: «El comerciante está unido con los otros comerciantes en un círculo, que tiene un gran número de intereses comunes: la legislación político-económica, el prestigio social de la clase comercial, la representación de la misma, [...], hace que la clase aparezca como una unidad frente a los demás ${ }^{53}$.

48. De un modo parecido a Simmel se expresa Mead, al enfatizar el proceso de comunicación social en el mercado: "El proceso económico debe ser tal que el individuo se identifique con los posibles parroquianos con los que intercambia cosas [...]. Si se quiere proseguir exitosamente con el proceso económico, es necesario entrar en una relación más estrecha con el otro individuo, identificarse con él, no sólo en la cuestión particular del intercambio, sino también averiguar qué necesita y por qué lo necesita, cuáles serán las condiciones de pago, las características especiales» (MEAD, G. H. (1982). Espíritu, persona y sociedad. Barcelona: Paidos Estudio, p. 311).

49. Simmel, G. Sociología. Estudios sobre la socialización, o. c., p. 306.

50. Ibídem, p. 321.

51. Ibídem, p. 323.

52. Ibídem, p. 311. Nos encontramos aquí con un tema de especial interés en el estudio de las relaciones sociales en el mercado (Cfr. Kellerhals, J.; Coenen-Hither; ModaK, M. (1988). Figures de l'equité, la construction des normes de justice dans les groupes. París: PUF).

53. Ibídem, p. 447- 448. 
Sin duda, esta combinación de competencia y cooperación es una fiel expresión de las múltiples relaciones y lazos que entretejen el tejido económico en el que se desarrollan solidaridades parciales. El estudio de los distritos industriales y de otras experiencias productivas ha puesto de relieve el modo en que se urden simultáneamente relaciones de competencia y de cooperación.

\section{La información, la confianza y la negociación}

La información y la confianza afectan muy directamente a las oportunidades de intercambio, a la negociación y al cumplimiento de los acuerdos en el contexto de los mercados.

A la sociología económica le interesa observar el papel que desempeña la información y la confianza, y el modo en que se construyen socialmente en los contextos de mercado ${ }^{54}$. La sociología clásica prestó bastante atención a estos temas y se interesó por los procedimientos mediante los cuales se introduce certidumbre en el sistema económico, para facilitar un funcionamiento fluido de las actividades productivas ${ }^{55}$.

Para Simmel, el crecimiento de las exigencias de coordinación en una economía más compleja nos revela la importancia que tiene la confianza para poder tomar decisiones y adquirir compromisos ${ }^{56}$. En todo caso, cualquier decisión entraña un riesgo, de modo que tienen siempre un carácter tentativo o de ensayo ${ }^{57}$. Durkheim sostenía que la fluidez de las relaciones económicas

54. Ibídem. Además de las contribuciones teórico-sociológicas de Coleman, de Luhmann y de Giddens, se ha desarrollado un interés por el estudio de la confianza y el capital social en la sociología económica (Cfr. Chistel Lane y Reinhard BaCHMAnN (eds.) (1968). Trust within and between Organizations. Oxford University Press).

55. Como precisa Swedberg: «Una sociología económica de los mercados debería también estudiar qué cambios en los mecanismos de intercambio hacen que el desarrollo capitalista sea más rápido o qué cambios provocan una reducción en su ritmo o incluso paralizan dicho desarrollo» (SWEDBERG, R. (2005). "Toward a Economic Sociology of Capitalism». En: L'Année Sociologique, 55, n o 2, p. 429).

56. Dice Simmel: «Mucho más ampliamente de lo que suele pensarse descansa nuestra existencia moderna sobre la creencia en la honradez de los demás, desde la economía, que es más economía de crédito, al cultivo de la ciencia, en la cual los investigadores, en su mayoría, tienen que aplicar resultados hallados por otros y que ellos no pueden comprobar. Construimos nuestras más transcendentales resoluciones sobre un complicado sistema de representaciones sociales, la mayoría de las cuales supone la confianza de que no somos engañados» (Simmel, G. Sociología. Estudios sobre las formas de socialización, o. c., p. 363).

57. Simmel era muy consciente de los límites de la información y de la inseguridad que supone la relación y la colaboración con otras personas: «Por motivos arraigados en lo más hondo y valioso de la naturaleza humana, puede decirse que la colocación de un hombre en un nuevo poder o en una nueva función representa siempre un riesgo, aunque se hayan hecho las pruebas más escrupulosas, y se tengan los antecedentes más seguros; es siempre un ensayo que puede resultar o no. La relación que el hombre mantiene con el mundo y con la vida nos obliga a resolver antes de antemano; es decir, a producir por nuestra resolución aquellos hechos que deberían ser ya producidos y conocidos, para poder tomar la resolución racionalmente y con seguridad» (ibídem, p. 172-173). 
podría verse afectada y, por tanto, la actividad productiva paralizada si no existiese un mínimo de normas compartidas, pues, de lo contrario, se producirían continuos regateos y dificultades de interpretar lo pactado ${ }^{58}$. En otras palabras, sería necesaria una estructura social e institucional que redujese los costes de transacción. Weber se preguntaba por las razones que explicarían el cumplimiento de lo pactado en el mercado. Entre otras razones, señalaba el interés de mantener una relación a largo plazo, el sentido del deber, la desaprobación social, el control de la comunidad y, cada vez más en una sociedad compleja, el sistema jurídico como sistema de garantía y salvaguarda ${ }^{59}$.

El problema de la incertidumbre y, en particular, de la confianza viene preocupando a los economistas y a los teóricos y sociólogos de las organizaciones ${ }^{60}$. $\mathrm{K}$. Arrow ha sido uno de los primeros economistas que ha reconocido el valor económico de la confianza, al considerarla como una suerte de lubricante para la vida económica. En este sentido, apunta: «Es muy eficiente y ahorra cantidad de problemas el que en un cierto grado pueda confiarse en la palabra del otro» ${ }^{61}$.

Las inteligentes reflexiones de Simmel tienen un carácter pionero. Para Simmel, la confianza se sitúa a medio camino entre el conocimiento absoluto y la ignorancia: «El que sabe no necesita confiar; el que ignora no puede siquiera confiar» ${ }^{62}$. En efecto, la confianza se basa en algún tipo de indicio que reduce la incertidumbre en relación con el comportamiento de los otros, adoptando formas diferentes según el tipo de estructura social. Mientras que, en las sociedades tradicionales, la confianza compromete a la totalidad subjetiva del individuo, en las modernas, las relaciones son más impersonales y la confianza, esa hipótesis en relación con la conducta futura del otro, afecta tan sólo a una prestación específica y objetivada.

Entre los ejemplos con los que nos ilustra, contempla, entre muchos otros, el mundo económico y el mundo científico orientado a la innovación y a la producción de conocimientos ${ }^{63}$.

En sus ensayos sobre las formas, también nos descubre el papel del secreto y la mentira que nos permite entender los juegos estratégicos que tienen lugar en el mercado. El secreto, que está ligado al valor social de la privacidad ${ }^{64}$, da un tono a las relaciones económicas. La cantidad de secreto que pueda existir entre dos individuos o grupos contribuye a caracterizar las relaciones entre

58. Durkheim, E. (1982). La división del trabajo social. Madrid: Akal, p. 253. y p. 429-430.

59. Weber, M. (1984). Economía y sociedad. México: FCE, p. 272.

60. Cfr., StinchCombe, A. L. (1990). Information and Organizations. Oxford: University of California Press.

61. Arrow, K. (1974). The Limits of Organizations. Nueva York: W. W. Norton, p. 23.

62. Simmel,G., Sociología. Estudios sobre las formas de socialización, o. c., p. 363.

63. «El comerciante moderno que trata un negocio con otro, el sabio que emprende una investigación [...] saben de la parte con quien se entienden exactamente lo que hace falta para la relación que se establece. Las tradiciones e instituciones, el poder de la opinión pública [...] se han hecho tan firmes y seguros, que basta conocer ciertas exterioridades referentes al otro, para poseer la confianza necesaria a la acción común» (ibídem, p. 367).

64. Ibídem, p. 383. 
ellos. El secreto, que puede ser legítimo, también es un medio para ocultar actividades ilegítimas. De ahí los esfuerzos por introducir transparencia en muchos órdenes institucionales. En la Filosofía del dinero se presenta un tema de gran interés para la sociología económica, relativo a la transparencia de las cuentas públicas y de la administración en las grandes sociedades anónimas ${ }^{65}$. Los frecuentes escándalos financieros y políticos ponen al descubierto este viejo problema de control de las grandes corporaciones.

Además de la ocultación y el secreto, la mentira supone una información manipulada. La mentira tiene tal grado de importancia que «las estructuras sociológicas se distinguen de un modo característico según el proceso de mentira que alientan en ellas» ${ }^{66}$. La manipulación del conocimiento es un medio de poder y una táctica en un juego estratégico. Decía Simmel: «El valor negativo que, en lo ético, tiene la mentira, no debe de engañarnos sobre su importancia sociológica, en la confrontación de ciertas relaciones concretas» ${ }^{67}$.

Pero el uso del engaño no es ilegítimo en todas las situaciones ${ }^{68}$. Piénsese, por ejemplo, cuando un hábil negociador consigue engañar a la otra parte sobre sus intenciones o su capacidad de resistencia. Tema que nos conduce al terreno de la negociación y el regateo.

Las reflexiones de Simmel sobre la negociación y el conflicto adquieren un gran interés a la luz de la perspectiva estratégica para el estudio del mercado $\mathrm{y}$, en particular, de la determinación de las condiciones laborales en el mercado de trabajo.

En su Filosofía del dinero se apuntan los rasgos de un breve modelo de negociación, en el que nos revela la dificultad de que las partes puedan conocer de antemano la correlación de fuerzas, anticipando el resultado de la lucha y evitando incurrir en el conflicto abierto (p. ej., una huelga) ${ }^{69}$. Como dicha representación precisa es difícilmente imaginable, la negociación siempre supone el riesgo de que se desencadene una huelga.

65. «Si los órdenes jurídicos modernos imponen el carácter público de la contabilidad de los Estados y de las sociedades anónimas, en realidad los peligros que se tratan de evitar emanan, principalmente, de la forma monetaria de las actividades, de la facilidad de la ocultación, del cálculo erróneo, del empleo ilegítimo, todos los cuales constituyen peligros para los terceros que [...] únicamente se pueden evitar, en cierto modo, por medio de la publicidad de los negocios» (Simmel, G. Filosofía del dinero, o. c., p. 479).

66. Simmel, G. Sociología. Estudios sobre la socialización o. c., p. 362.

67. Ibídem, p. 365.

68. Simmel se refiere también a la falsedad y al engaño en el ámbito de la competencia (ibídem, p. 323).

69. En sus propias palabras: «Piénsese, por ejemplo, en las negociaciones entre trabajadores y empresarios con el fin de evitar una huelga en ciernes. En este caso cada parte procura hacer concesiones tan sólo hasta aquel punto en que, según la valoración de las fuerzas en juego, la huelga real se le impondría como obligación. Se procura evitar el último ratio en la medida en que se anticipa su resultado en una representación resumida. Si esta medición de las fuerzas [...] fuera siempre posible con seguridad, podría evitarse toda lucha [...] de no ser porque su reproducibilidad es un presupuesto imposible» (Simmel, G. Filosofía del dinero, o. c., p. 148-149). 
La perspectiva estratégica para el estudio sociológico de la negociación y del conflicto, se ha interesado por este asunto indicando algunos factores para explicar estos fenómenos. En primer lugar, los dilemas estratégicos que se plantean como consecuencia de que los actores sean grupos (asociaciones empresariales, sindicatos, etc.) a los que no puede aplicárseles una teoría de la decisión individual. En segundo lugar, la necesidad de considerar la complejidad de los actores colectivos, que está asociada a su tamaño, y su relación con la inercia a la movilización conjunta ${ }^{70}$.

Estos temas relativos a la naturaleza corporada de los actores preocuparon a Simmel. En el caso de los sindicatos, el tamaño y la complejidad generan dilemas estratégicos, pues «al aumentar la extensión pierden en cohesión interna ${ }^{71}$. También nos pone de relieve cómo, con motivo de los cambios técnicoorganizativos, se enfrentaban entre sí las diversas ocupaciones, situación de la que obtenían ventaja los patronos por su posición de tertius gaudens ${ }^{72}$.

Finalmente, contempla el ámbito de negociación. Que éste sea de empresa, sectorial o intersectorial es un hecho crítico en las relaciones industriales. Simmel señalaba cómo los patronos se negaban a negociar con «intermediarios» no pertenecientes a sus trabajadores. Se intentaba evitar, de este modo, que se vinculasen a un representante que nada tenía que temer del patrono, lo que obstaculizaba la acción uniforme y el «establecimiento de unas tarifas colectivas de salario» ${ }^{73}$. Se buscaba imponer una política de divide et impera.

Con todo, quedaba abierto un dilema estratégico: ¿Qué es preferible, optar por negociaciones ordenadas y estructuradas en torno a dos grandes organizaciones o la alternativa de las negociaciones fraccionadas y atomizadas? A juicio de Simmel, la respuesta no está clara: «Podría creerse que cada parte ha de tener el mayor interés en que la parte contraria carezca de unidad. Y, sin embargo, hay casos de lo contrario [...] Pues si bien las huelgas en este caso son más extensas y duraderas, en cambio la organización es para ambas partes más favorable y menos cara que los numerosos rozamientos locales [...], inevitables cuando no hay organización sólida entre ambas partes». Y además, concluye, con organizaciones representativas se introduce mayor certidumbre en el cumplimiento de lo pactado ${ }^{74}$.

El caso que presenta Simmel ilustra bien dos fenómenos, el de la dependencia y el de la incertidumbre, que se han utilizado para dar cuenta de la

70. Adams, G., Reynaud, J. D. (1978). Conflicts du travail et changement social. París: PUF, p. 112 y s.

71. Simmel, G. Sociología. Estudios sobre las formas de socialización, o. c., p. 65.

72. Para Simmel, los cambios en el tamaño de un grupo introducen variaciones cualitativas. Así, por ejemplo, con la aparición de un tercero, emergen nuevas situaciones de interacción y nuevos escenarios. El tercero no sólo puede actuar como mediador, sino que puede obtener ventajas del conflicto o de la competencia de las otras partes (tertius gaudens) o, incluso, provocar de un modo consciente la tensión entre las partes para obtener una ventaja (divide et impera).

73. Ibídem, p. 131.

74. Ibídem, p. 327-328. 
naturaleza del entorno de las organizaciones ${ }^{75}$. Dos dimensiones que también pueden contribuir a caracterizar «la estructura social de los mercados», al estar asociadas a las relaciones de poder y a los problemas de la confianza.

\section{A modo de conclusión}

Existe un hilo conductor entre estas contribuciones que nos permite reivindicar a Simmel como un referente clásico de la sociología económica.

Este reconocimiento de la obra de Simmel parece necesario, pues, transcurridos más de veinte años desde el renacimiento de la sociología económica, la recepción de su obra es limitada. En comparación con otros clásicos, sólo se le cita en contadas ocasiones. Unas veces para recordar su contribución al análisis de las redes, otras para dar cuenta de algún aspecto aislado de la vida económica (el dinero, la moda, el intercambio, etc.).

En ningún momento se ha observado que en su obra se encuentren los elementos necesarios para construir sistemáticamente los fundamentos de una sociología del mercado. Es aquí donde creemos que reside la originalidad de nuestro trabajo.

En nuestro artículo, hemos comenzado poniendo de relieve el interés de Simmel en dar cuenta del papel que desempeñan el solapamiento de los círculos sociales y las redes sociales en la generación de innovación. El espacio urbano es el lugar por excelencia para el desarrollo de la innovación y para la diferenciación de los mercados. En este medio urbano, tiene lugar un proceso de racionalización, sin el cual difícilmente podríamos explicar las dimensiones que actualmente ha adquirido el mercado. A su vez, esta compleja construcción social e institucional, puede observarse como un espacio de interacciones sociales.

Esta interpretación se desprende de algunas ideas sobre las formas sociales que Simmel nos presenta de un modo fragmentario. Se trata de diversos tipos de relación social que, como la competencia, el intercambio y el regateo, constituyen el núcleo del mercado y cuyo comportamiento no puede entenderse analizándolos independientemente. A su vez, Simmel reflexiona sobre la confianza, el secreto o la mentira que igualmente contribuyen a caracterizar las estructuras sociales y a explicar los procesos sociales del mercado.

Al tratar de reconstruir la idea del mercado, observamos cómo en los diversos fragmentos que rescatamos, nos encontramos con elementos de la teoría del intercambio, con algunas ideas que han contribuido al desarrollo de una teoría pluralista del conflicto, con los rudimentos del análisis estratégico, con un primer esbozo del enfoque de las redes y con algunos pilares de lo que, con el tiempo, se denominará interaccionismo simbólico.

75. Cfr. Thompson, J. D. (1993). Organizaciones en acción. Londres: McGrawHill, p. 31 y s.; cfr. ScOtT, W. R. (1981). Organizations: Rational, Natural and Open System. Nueva York: Prentice-Hall. 
En estas conclusiones queremos subrayar como, en el trabajo de Simmel, se muestra el interés de una perspectiva interaccionista en el estudio del mercado. Esta perspectiva nos revela que las formas sociales que propone Simmel no tienen un carácter estático o meramente clasificatorio. Es decir, no pueden entenderse en meros términos morfológicos ${ }^{76}$, pues, a través de los procesos de interacción, emergen nuevas características y propiedades que ayudan a reconfigurar las relaciones. A través de las relaciones sociales implicadas, Simmel nos invita a pensar el mercado desde una perspectiva que enfatiza el carácter dinámico de la interacción y de la comunicación.

Sin olvidar los procesos de institucionalización, a Simmel le interesa destacar las propiedades «emergentes» de los procesos interactivos, distanciándose tanto de una versión sobresocializada como de una infrasocializada. Por una parte, se aleja de una visión estática y formalista del mercado y del atomismo que caracteriza el modelo económico neoclásico. Por otra, al situar en un primer plano los procesos de aprendizaje que tienen lugar en el mercado, se aproxima a una perspectiva evolucionista y pragmática que encontrará en Veblen, Cooley y Mead sus mejores representantes.

Simmel estudia los aspectos microsociales sin desentenderse de los aspectos macrosociales y de los procesos evolutivos. Pero, al hablar de las formas sociales del mercado, pone más el acento en los procesos fluidos que en los elementos institucionalizados. Serán Emile Durkheim, Max Weber y Charles Horton Cooley, entre otros, quienes se ocuparon más del papel que desempeñan las instituciones en la reducción de la incertidumbre, en la inyección de confianza y en la organización social de los mercados.

Si algo tiene que interesar a una sociología económica del mercado es el análisis de las formas que adoptan las relaciones sociales en su interior y las consecuencias que se derivan para su desarrollo. A Simmel se le debe considerar como un clásico de la sociología económica, no sólo por su magistral Filosofía del dinero, sino también, tal como hemos puesto de relieve a lo largo de estas páginas, porque establece los fundamentos de una sociología del mercado a partir de una reflexión sobre la naturaleza de las relaciones sociales.

\section{Referencias bibliográficas}

ADAMS, Gérard; REYNAUD, Jean Daniel (1978). Conflicts du travail et changement social. París: Presses Universitaires de France.

ARrow, Kenneth (1974). The Limits of Organizations, Nueva York: W.W. Norton. Aspers, Patrick (2006). "Markets Structures». En: BeCKerT, J.; ZAFIrOvsKi, M. International Enciclopedy of Economic Sociology. Londres: Routledge.

Berger, Peter; LuCKMAN, Thomas (1972). La construcción social de la realidad. Buenos Aires: Amorrortu.

76. Vandenberhe, Frédéric (2001). La Sociologie de George Simmel. París: La Decouverte, p. $40-41$. 
Block, Fred (1990). Posindustrial Possibilities. A Critique of Economics Discourse. Berkeley: University California Press.

Castells, Manuel; Hall, Peter (1994). Las tecnópolis del mundo. Madrid: Alianza Editorial.

Castillo Castillo, José (1996). "Trabajo y consumo». En: OrTega, F. y otros. Fundamentos de Sociología. Madrid: Síntesis.

Coser, Lewis A. (1970). Nuevos apuntes a la teoría del conflicto social, Buenos Aires: Amorrortu.

Degenne, Alain; Forsé, Michel (2004). Lés réseaux sociaux, París: Armand Colin. Deutschmann, Christoph (2000). "Capitalism as a Religion? An Unortodox Analysis of entrepreneurship: The return of Economic Sociology in Europe». European Journal of Social Theory, 4(4): 387-403.

DURKHEIM, Emile (1982). La división del trabajo social. Madrid: Akal.

Fligstein, Neil (2002). "Agreements, Disagreements and Opportunities in the "New Sociology of Markets”». En: Guillen, Mauro F.; Collin, Randall; EnGLAND, Paula; Meyer, Marshall. The New Economic Sociology. Developments in a Emerging Field. Nueva York: Russell Sage Foundation.

García Blanco, José María (2000). «Sociología y sociedad en Simmel». Revista Española de Investigaciones Sociológicas, 89, enero-marzo, p. 97-117.

GranOVETTER, Marc (1973). «The strength of weak ties». American Journal of Sociology, 78 , p. $1360-1380$.

- (1985). "Economic Action and Social Structure: The Problem of Embeddedness», en American Journal of Sociology, vol. 1, 91, p. 481-510. Traducción. española en REQUENA SANTOS, Félix (2002). Análisis de redes sociales: Orígenes, teorías y aplicaciones. Madrid: Centro de Investigaciones Sociológicas.

- (1990). "The Old and the New Economic Sociology». En: Friedland, R.; Robertson, A. F. (ed.). Beyond the Marketplace. Nueva York: Aldine de Gruyter. InGHAM, Geoffrey (1996). "Some Recent Changes in the Relationship between Economics and Sociology». Cambridge Journal of Economics, vol. 20, no 2, marzo, p. 243-275.

Kellerhals, Jean; Coenen-Hither, Josette; ModaK, Marianne (1988). Figures de l'equité, la construction des normes de justice dans les groupes. París: Presses Universitaires de France.

LAMO DE ESPINOSA, Emilio y otros (1994). La sociología del conocimiento y de la ciencia. Madrid: Alianza Universidad.

Lane, Christel; Bachmann, Reinhard (eds.) (1968). Trust within and between Organizations. Oxford: Oxford University Press.

MEAD, George H. (1972). Espiritu, persona y sociedad. Barcelona: Paidós Estudio. ORTEGA y GASSET, José (1986). «Los escaparates mandan». El Sol, 15 de mayo de 1927. En: ORTEGA Y GASSET, José (1986). La rebelión de las masas. Madrid: Espasa Calpe.

PORTES, Alejandro (1995). «Economic Sociology and the Sociology of Inmigration: a Conceptual Overview». En: PORTES, Alejandro (ed.). The Economic Sociology of Inmigration. Nueva York: Russel Sage Foundation.

REQUENA SANTOS, Félix (2002). Análisis de redes sociales: Orígenes, teorías y aplicaciones. Madrid: Centro de Investigaciones Sociológicas.

ScOTт, W. Richard (1981). Organizations: Rational, Natural and Open System. Nueva York: Prentice-Hall.

Simmel, Georg (1907). «Soziologie der Sinner». Die neue Rundschau, 18, p. 1025-1036. 
- (1977). Filosofía del dinero. Madrid: Instituto de Estudios Políticos.

- (1986). «Las grandes urbes y la vida del espíritu». En: SimmeL, G. El individuo y la libertad: Ensayos de crítica de la cultura. Barcelona: Península.

- (1986). El individuo y la libertad: Ensayos de crítica de la cultura. Barcelona: Península.

- (1986). Sociología: Estudios sobre la socialización. Madrid: Alianza Editorial.

- (1988). Sobre la aventura: Ensayos filosóficos. Barcelona: Península.

SMelser, Neil; SwedberG, Richard (1994). Handbook of Economic Sociology. Nueva Jersey: Princeton University.

SOLÉ, Carlota (1998). Modernidad y modernización. Barcelona: Anthropos.

STEINER, Philippe (2002). La sociologie économique. París: La Découverte.

STINCHCOMBE, Arthur L. (1990). Information and Organizations. Oxford: University of California Press.

SwEDBERG, Richard (1987). «Economic Sociology: Past and Present». Current Sociology, vol. 1 .

- (2005). «Toward a Economic Sociology of Capitalism». L'Année Sociologique, 55, n $\circ 2$, p. 419-450.

ThOMPSON, James D. (1993). Organizaciones en acción. Londres: McGrawHill.

VAndenberhe, Frédéric (2001). La sociologie de George Simmel. París: La Découverte. Weber, Max (1984). Economía y sociedad. México: Fondo de Cultura Económica.

Weinstein, Deena; Weinstein, Michel A. (1990). «Simmel and the Theory of Postmodern Society». En: BrYAn, S. T. (ed.). Theories of Modernity and Postmodernity. Londres: Sage.

ZeLIZER, Viviana (1978). «Human Values and the Market: the Case of Life Insurance and Death in $19^{\text {th }}$ Century America». American Journal of Sociology, 84, p. 591-610.

- (1992). «Repenser le marché, la construction sociale du "marché aux bebés" aux États-Unis, 1870-1930». Actes de la Recherche en Sciences Sociales, 94, septiembre, p. 3-26. 